\title{
Health Practices and Classroom Engagement of Minority Pupils in the Southern Philippines
}

\author{
Salvador R. Torcuator III (Corresponding author) \\ College of Education, Mindanao State University - General Santos City Campus \\ Purok Uno-A, Lun Masla, Malapatan 9516, Sarangani, Philippines \\ E-mail: torcuatorsalvadorIII@gmail.com
}

\author{
Michael B. Cahapay \\ College of Education, Mindanao State University - General Santos City Campus \\ Fatima, General Santos City 9500, South Cotabato, Philippines \\ E-mail: mbcahapay@up.edu.ph
}

Received: May 6, 2020

Accepted: June 30, 2020

Published: June 30, 2020

doi:10.5296/gjes.v6i1.16987

URL: https://doi.org/10.5296/gjes.v6i1.16987

\begin{abstract}
When pupils are physically healthy, they engage actively in classroom activities and perform higher in their learning. This study aimed to determine the relationship between health practices and classroom engagement. This study employed a correlational research design. It involved all sixty-three (63) minority pupils in a public elementary school in Sarangani Province in the southern Philippines during the school year 2015-2016. Tailored and modified questionnaires were used to gather the needed data. The statistical tools employed in the analysis were frequency count, percentage rate, weighted mean, and Pearson Product Moment Correlation Coefficient. The results showed that pupils display health practices to a great extent. They also exhibit a high level of classroom engagement. The analysis further revealed that there is a moderately significant relationship between health practices and classroom engagement. Hence, this study provides evidence as regards the influence of the health practices on classroom engagement. It is recommended that more comprehensive researches should be conducted in different contexts, with larger samples, and exploring the influences of other relevant variables.
\end{abstract}

Keywords: Health practices, Classroom engagement, Elementary education, Minority pupils 


\section{Introduction}

Health practice is the health routine of an individual as a way to prevent diseases. Many indigenous peoples have their practices in attaining good health. Diverse cultures bring different ways of their health practices. Based on what they perceived to be sufficient, their belief drives them to put the concept of health attainment to their action, unaware of the possible implications which experts had already expressed to their studies.

The United Nations Department of Economic and Social Affair (2009) estimated that indigenous peoples constitute 370 million individuals, representing more than 5000 distinct peoples, living in more than 90 countries in all inhabited areas. Lack of sanitation contributes to about $10 \%$ of the global disease burden (Mara et al., 2010). The inadequacy of health practices is still a serious global issue, specifically in schools and the academic performance of the indigenous groups.

Common childhood illnesses in the Philippines are still prevalent with pneumonia and diarrhea remaining the leading causes of child mortality (Bermejo et al., 2015). The problems on health such as inadequate practices, an increase in disease infection rate and insufficient food acquisition are among the reasons for absenteeism among the pupils. Locally, a public elementary school in Sarangani Province in the southern Philippines was mostly dominated by minority people and some struggles from a deficiency in nutritional status. According to the secondary data on the 2015 school nutritional status, $35.67 \%$ of the population of boys and girls coming from intermediate grades have a nutritional status deficiency. Thus, this affects more the health of the children in society including the tribal minority.

Some theories and concepts can be reframed to show the influence of health practices on classroom engagement (Maslow, 1954; Jensen, 2013). However, in research, most scholars have explored the association between the different health dimensions and academic achievement (Brown et al., 2008; Willms, 2009; Farooq et al., 2011; Suhrcke \& de Paz Nieves, 2011; Hanks et al., 2012; Jensen, 2013; Esmalla, 2014; William, 2014; Gomes et al., 2015; McIsaac et al., 2015; Michael et al., 2015; Sabia et al., 2015; Bueno et al., 2017; Yansaputri \& Wijaya, 2017; Xiang et al., 2017; Marques et al., 2018; Matingwina, 2018; Cheon, 2019; O’Connor et al., 2019; Barth Vedoy, 2020; Kovess-Masfety et al., 2020). Aside from the overlook on classroom engagement variable and diffused results on the relationship between the two variables, it is also assumed that these studies were conducted in the context of the mainstream society.

The current paper is both related and different in some respects. It will specifically explore the relationship between health practices and classroom engagement. The construct of classroom engagement is different from academic achievement; it is a multifaceted construct that refers to the meaningful involvement of the learners (Martin \& Torres, 2016) throughout the classroom. Aside from the general perception on the inadequacy on health awareness as a societal issue that demands an appropriate response, this study is different from the previous studies in the aspect that it will attempt to focus on the context of a group of minority learners which have not been well explored in the research. 


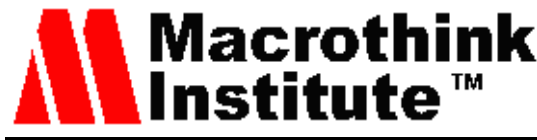

Global Journal of Educational Studies

ISSN 2377-3936

2020, Vol. 6, No. 1

The conduct of this study is significant to school administrators, teachers, parents, pupils, and researchers. This may provide tangible data on how health practices affect classroom engagement in some respects and may provide appropriate health awareness in well-lifestyle to the balanced-health status. This may also help foster understanding of the health habits being practiced by a minority group, and offer insights and systematic observations of the health implications. Thus, this may be used to support and clarify existing related literature.

\section{Research Questions}

This study aimed to determine the health practices and its influence on classroom engagement of the minority pupils in the Southern Philippines.

Specifically, this attempted to answer the following questions: 1. What is the extent of the health practices of minority pupils? 2. What is the level of classroom engagement of the minority pupils? 3 . Is there a significant relationship between the health practices and classroom engagement of the minority pupils?

\section{Theoretical Framework}

This study is grounded on the theory of the Hierarchy of Needs by Abraham Maslow (1954). The theory posited deficiency needs before growth needs. And within the deficiency needs, lower needs must be met before moving on to the next higher level, as such, physiological needs including the most basic needs that are essential to survival which is the need for water, air, food, and sleep, that combats hunger, thirst and provides bodily comforts must be satisfied first (Huitt, 2007). The theory emphasizes the perspective that physiological needs, the most basic and instinctive needs, must be fulfilled first because all needs become secondary until these physiological needs are met, which matches this study that health practices are needed to foster engage learners in the classroom activities. Social needs are also important but they are not as demanding as physiological needs.

When students experience poor nutrition and diminished health practices, it is more difficult for them to listen, concentrate, and learn (Jensen, 2013) and unhealthy students are less likely to accomplish tasks. Thus, it is harder to meet the desired outcome. This, in turn, reduces the interaction between classroom engagement among pupils. Moreover, healthier students are also better learners (Centers for Disease Control and Prevention, 2014), being physically fit is associated with school success (Gomes et al., 2015), and the consumption of healthy food corresponds to higher academic performance (Woodhouse \& Lamport, 2012). Studies justify that learners who practice better health habits are more likely to participate in class activities very well.

Based on the above theory, this research conceptualizes that the independent variable which is health practices is significantly related to the dependent variable which is classroom engagement. This research shows that the more adequate health practices, the better the classroom engagement. The theoretical framework was developed in conjunction with the problems stated in the study that seeks to determine the significant relationship between health practices of pupils and their classroom engagement. 


\section{Research Methodology}

This study employed a correlational research design. A correlational research design measures a relationship between two variables without the researcher controlling either of them. It aims to find out whether there is either positive correlation, negative correlation, or zero correlation (McCombes, 2019). Thus, the correlational research design is primarily used to determine how the independent variable influences the dependent variables; to establish the relationship between these variables. It is appropriate for the current study as it attempted to determine the relationship between health practices and classroom engagement of the pupils.

The respondents of the study were the purposively selected 63 pupils coming from Grades V and VI. They were enrolled in a public elementary school during the school year 2015-2016. Based on the class records, these pupils were identified by the advisory teachers as belonging to the minority tribes. Moreover, pupils have an age range between 11 and 13, a period of beginning maturation. The children in these ages go through big physical changes in puberty and need extra nutrition to fuel these physical changes. The level of physical activity and stage of development of the children determine exactly how much healthy food is needed (The Australian Parenting Website, 2015).

This study was conducted in a public elementary school, located in a rural area in a town in Sarangani Province in the southern Philippines. The school is mostly dominated by pupils coming from minority tribes. The population of the school diversely consists of different minority groups around the rural area. It is observed that the lack of resources and awareness also led to the inadequacy of health practices among the pupils.

Two survey scales were used in collecting the data for this study, First, the Health Practices Scale, composed of 15 items, was formulated in reference to the ideas and insights based on readings of the related literature. It was validated by field experts and pilot tested. It obtained a validation score of 4.33 and a reliability index of 0.754 , which suggest that the tailored scale has high validity and good reliability. Second, the Classroom Engagement Scale, composed of 15 items, was primarily modified from Chamber (2000) and other references. It was subjected to pilot testing. It generated a reliability index of 0.740 which implied good reliability for use in the research.

The researcher employed frequency count, percentage rate, and weighted mean to interpret the gathered data. Furthermore, Pearson Product Moment Coefficient Correlation was used to measure the strength of a linear association between two variables (Laerd Statistics, 2013). The test was done at 0.05 level of significance. 


\section{Results and Discussion}

Table 1. Health practices of the pupils

\begin{tabular}{|l|c|c|c|}
\hline \multicolumn{1}{|c|}{ Indicators } & Mean & Description & Interpretation \\
\hline 1. I wash my hands after using toilet & 4.48 & Often & Great extent \\
\hline 2. I wash my hands before and after meals & 4.48 & Often & Great extent \\
\hline 3. I wash my hands with soap when it's dirty & 4.49 & Often & Great extent \\
\hline 4. I wash my hands frequently in a day & 4.67 & Always & Very Great extent \\
\hline 5. I brush my teeth every day & 4.10 & Often & Great extent \\
\hline 6. I clean my ears with cotton buds & 4.46 & Often & Great extent \\
\hline 7. I dispose my trash in trash bins & 4.32 & Often & Great extent \\
\hline 8. I use the right amount of water for cleansing & 4.32 & Often & Great extent \\
\hline 9. I eat vegetables & 4.16 & Often & Great extent \\
\hline 10. I eat fruits & 3.73 & Often & Great extent \\
\hline 11. I drink water at least eight glasses a day & 3.51 & Often & Great extent \\
\hline 12. I don't eat junk foods & 4.43 & Often & Great extent \\
\hline 13. I eat on time & 3.97 & Often & Great extent \\
\hline 14. I exercise regularly & 4.02 & Often & Great extent \\
\hline 15. I take at least 8 hours of sleep a day & 4.11 & Often & Great extent \\
\hline Overall mean & 4.21 & Often & Great extent \\
\hline
\end{tabular}

The health practices of the pupils as indicated by mean, description, and interpretation.

The data show that the pupils always wash their hands too frequent and several times a day $(\mathrm{M}=4.67)$. They often wash their hands with soap when it is dirty $(\mathrm{M}=4.49)$; before and after meal $(\mathrm{M}=4.48)$; and even after using toilet $(\mathrm{M}=4.48)$. This is a reflection of how the parents teach their children the habitual cleaning of hands with water and soap. Hubley et al. (2013) explained that one of the forms of transfer of habits may occur from how parents establish habitual basic healthy paradigms to their children including hand-washing, and that could be the reason why children regularly wash their hands.

Moreover, the pupils often clean their ears with cotton buds $(M=4.46)$. It can be noticed that children frequently manipulate their ears using appropriate materials during childhood. Richards (2016) explained that the ears are packed with sensitive nerve endings, using buds triggers those nerve endings eventually causes visceral pleasure.

Furthermore, the pupils often dispose their trashes in trash bins $(M=4.32)$. This indicates that pupils practice proper waste disposal. This could be an outcome of the Department of Education Order No. 72, known as the establishment of YES-Organization that mandates the implementation of waste management, segregation, and recycling programs to develop proper community environmental values, skills, and attitudes.

Lastly, the pupils often use the right amount of water for cleansing $(M=4.32)$. This reflects 
the values shown by pupils on water conservation. This could be attributed to the Department of Education Science Curriculum in which one of the content standards is the conservation of water and other natural resources.

Generally, health practices being exercised by pupils garnered a weighted mean of 4.21 described as often. This implies that most of the pupils display health practices to a great extent. The highlighted items show that the pupils consistently and habitually wash their hands properly. This reflects the good health practice inculcated by their parents to their children despite the geographical setting of their houses, having to walk a long way to fetch water from a deep well for there is no water system reached in their place yet. Jiménez, et al. (2014) concluded that the profound traditional ecological knowledge and local practices of indigenous communities are still being practiced despite the geographical location and the lower access of water.

The findings of the study corroborate with the study conducted by Kwan, Petersen, Pine, and Borutta (2005) found out that elementary pupils practice good health to a great extent. Local studies of Esmalla (2014), Yabut (2014), and Percalin (2016) also found out that elementary pupils have a great extent of health practices. On the other hand, it has a different result than that of Leysa (2014) who concluded that pupils engage in health practices to a moderate extent.

Table 2. Classroom engagement of the pupils

\begin{tabular}{|l|c|c|c|}
\hline \multicolumn{1}{|c|}{ Indicators } & Mean & Description & Interpretation \\
\hline 1. I participate in class discussions and presentations & 4.10 & Often & High level \\
\hline 2. I memorize and familiarize our lesson & 4.35 & Often & High level \\
\hline 3. I finish homework for my lesson & 4.27 & Often & High level \\
\hline $\begin{array}{l}\text { 4. I include myself in classroom conversations that let me } \\
\text { reason out my thoughts }\end{array}$ & 4.03 & Often & High level \\
\hline 5. I ask or answer questions in class recitations & 4.27 & Often & High level \\
\hline $\begin{array}{l}\text { 6. I involve myself in activities such as drama activities } \\
\text { and role plays }\end{array}$ & 3.65 & Often & High level \\
\hline 7. I socialized with my other classmates in class activities & 3.89 & Often & High level \\
\hline $\begin{array}{l}\text { 8. I involve myself in challenging works like puzzle } \\
\text { solving, rumbled word construction or activities that } \\
\text { enable me to think deeply }\end{array}$ & 4.06 & Often & High level \\
\hline 9. I share my ideas with my classmates & 4.21 & Often & High level \\
\hline 10. I finish work given by my teacher on time & 4.19 & Often & High level \\
\hline 11. I consult my teacher regarding my scores & 3.87 & Often & High level \\
\hline $\begin{array}{l}\text { 12. I help my classmates while our teacher is busy helping } \\
\text { others with our lesson }\end{array}$ & 3.97 & Often & High level \\
\hline 13. I join classroom games and contest & 4.24 & Often & High level \\
\hline 14. I study for our quizzes & 4.25 & Often & High level \\
\hline 15. I learn things independently/on my own & 4.19 & Often & High level \\
\hline Overall mean & 4.10 & Often & High level \\
\hline
\end{tabular}


The classroom engagement of the pupils as indicated by mean, description, and interpretation.

The data above show that pupils often memorize and familiarize the lesson $(M=4.35)$. This means that memorization of lessons is a common form as a way of studying among elementary pupils. This could be ascribed to what Johnson (2010) stated that young children feel a sense of accomplishment when something has been memorized completely. Besides, the pupils often finish homework $(\mathrm{M}=4.27)$. This means that pupils have better orientation on assignment completion. Wenglinsky (2001) stated that peer and teacher pressure, family involvement, traditional behavior, and additional points motivate the children on completion of their homework.

The pupils often ask or answer questions in the class recitations $(M=4.27)$. This suggests that pupils display positive interaction in classroom discussions by raising related questions or giving responses to questions. Wurman (2015) stated the exhibition of creativity and curiosity about things and explore through various form of questioning are pieces of evidence of child development, and that they want to be rewarded by doing such.

Moreover, the pupils often study for quizzes $(M=4.25)$. This can be attributed to the frequent administering of formative assessments of teachers. Dunleavy (2008) stated that the use of assessments too often may improve the learning and study habits, develop a deeper understanding, widened the area of learning, and better presentation. Furthermore, they often join classroom games and contests $(\mathrm{M}=4.24)$. This means that pupils engage in classroom activities when presented in interactive forms like games. Coates (2007) stated that high levels of classroom collaborative engagement reflect students feeling validated within their classroom, particularly by participating in developmental activities such as games.

Lastly, they often share ideas with other classmates $(M=4.21)$. This can be ascribed to the reason that sharing ideas is a social activity and children during late childhood develop social interaction with their peers. Taylor and Parsons (2011) explained that a high level of participation of pupils may be caused by the interest of the students to have stronger relationships with other classmates.

As a whole, the classroom engagement of the pupils obtained a weighted mean of 4.10 described as often. This implies that pupils have a high level of participation in learning activities in the classroom.

The finding of the study is parallel with several researches conducted by Kuh et al. (2006), and Furrer et al. (2014), they all found out that university and elementary students have a high level of classroom engagement. Local studies of Siona (2016), Gabay (2016), and Cervantes (2016) likewise reveal that there are high levels of classroom engagement among elementary pupils. 
Table 3. Relationship between health practices and classroom engagement of the pupils

\begin{tabular}{|c|c|c|c|c|}
\hline Variables correlated & r-value & p-value & Extent of relationship & Remarks \\
\hline $\begin{array}{c}\text { Health practices and } \\
\text { classroom engagement }\end{array}$ & 0.631 & 0.000 & Moderate relationship & Significant \\
\hline
\end{tabular}

The relationship between the two variables as indicated by values.

The data reveal that there is a significant relationship between health practices and classroom engagement of pupils. This is supported by the r-value of 0.631 with a $p$-value of 0.000 . Moreover, the extent of the relationship is described as moderate. There are $39.82 \%$ of the classroom engagement can be influenced by health practices and $60.18 \%$ can be explained by other factors.

The result implies that health practices influence the classroom engagement of the pupils. It means that the greater the extent of health practices, the higher the level of classroom engagement of pupils.

The result of this study validates the concept of Hanks et al. (2012) who viewed that health practices are essential factors in the classroom engagement of the pupils. He stated that the encouragement of healthy practices such as proper food consumption, proper hygiene and sanitation, and regular exercise increase the participation of the students in school.

Moreover, the findings of this study corroborate with the studies (e.g. Willms, 2009; Suhrcke \& de Paz Nieves, 2011; Jensen, 2013; Matingwina, 2018) who found out that health practices and classroom engagement are highly correlated. It was revealed that better health practices indicate more classroom engagement. On the other hand, the results of the study refute the previous literature stating that health practices of pupils have no definite correlations to their school achievement (e.g. McIsaac et al., 2015; Farooq et al., 2011; William, 2014; Esmalla, 2014).

\section{Conclusion}

This study was guided by the general purpose to determine the health practices and its influence on classroom engagement of the minority pupils. Based on the findings, it can be concluded that the pupils display health practices to a great extent and have a high level of classroom engagement. Moreover, health practices and classroom engagement have a significant relationship. This conclusion implies that the greater the extent of health practices, the higher the level of classroom engagement of pupils.

This study poses several contributions to its theory and practice. It provides theoretical knowledge as regards the influence of health practices on classroom engagement. It offers a significant contribution to the current body of related research results affirming and negating the relationship between the two variables. Furthermore, as most studies are set in the mainstream communities, the current paper proposes practical evidence on the importance of health practices in the classroom engagement of the learners within the lens of the minority 
community. It likewise gives insights that teachers should promote health education to open opportunities that foster better classroom engagement among the learners.

Finally, the present study is restricted in the sense that only one context was considered and with a smaller sample. It should be further stressed that classroom engagement is an outcome of multidimensional variables such as learner motivation, parent involvement, school environment, community support, and others. Thus, considering these restrictions, more comprehensive researches should be conducted in different contexts, with larger samples, and exploring the influences of other relevant variables.

\section{References}

Alderfer, C. (1969). Existence, relatedness, and growth: Human needs in organizational settings. New York: Free Press.

Barth, V. I., Anderssen, S. A., Tjomsland, H. E., Skulberg, K. R., \& Thurston, M. (2020). Physical activity, mental health and academic achievement: A cross-sectional study of Norwegian adolescents. Mental Health and Physical Activity, 18, 100322. https://doi.org/10.1016/j.mhpa.2020.100322

Bermejo, R. III, Firth, S., Hodge, A., Jimenez-Soto, E., \& Zeck, W. (2015). Correction: Overcoming stagnation in the levels and distribution of child mortality: The case of the Philippines. PLOS ONE, 10(10). https://doi.org/10.1371/journal.pone.0141633

Brown, J., Beardslee, W., \& Prothrow-Stith, D. (2008). Impact of school breakfast on children's health and learning: An analysis of scientific research. Gaithersburg, MD: Sodexo Foundation. Retrieved from t.ly/9Ojf

Bueno, C., Pesce, C., Redondo, I., Lopez, M., Miguel, M., \& Vizcaino, V. (2017). Academic achievement and physical activity: A meta-analysis. Pediatrics, 140(6), e20171498. https://doi.org/10.1542/peds.2017-1498

Centers for Disease Control and Prevention. (2014). Health and academic achievement. Retrieved from t.ly/Cshm

Cervantes, M. (2016). Classroom engagement, attendance rate, and nutritional status: Their influence on academic performance of Pantawid Pamilyang Pilipinong Program beneficiary pupils (Undergraduate thesis, Mindanao State University, General Santos City, Philippines).

Cheon, H. (2019). The relationship among health fitness, academic achievement and grit of male high school students. The Korean Journal of Physical Education, 58(01), 133-146. https://doi.org/10.23949/kjpe.2019.01.58.1.10

Coates, H. (2007). A model of online and general campus-based student engagement. Assessment and Evaluation in Higher Education, 32(2), 121-141. https://doi.org/10.1080/02602930600801878

Department of Education. (2003). DepEd Order No. 72, series of 2003: Establishment of the Youth for Environment in Schools (YES) Organization. Retrieved from http://goo.gl/4evAUv 
Department of Education. (2012). K to 12 Curriculum Guide in Science.

Dunleavy, J. (2008). Bringing Student Engagement Through the Classroom Door. Education Canada, 48(4), 23.

Esmalla, J. (2014). Health practices and academic performance in Jose C. Catolico Elementary School (Undergraduate Thesis, Mindanao State University, General Santos City, Philippines).

Farooq, M., Chaudhry, A., Shafiq, M., \& Berhanu, G. (2011). Factors affecting students' quality of academic performance: A case of secondary school level. Journal of Quality and Technology Management, 7(2), 01-14. Retrieved from t.ly/DjDN

Furrer, C., Pitzer, J., \& Skinner, E. (2014). The influence of teacher and peer relationships on students' classroom engagement and everyday motivational resilience. National Society for the Study of Education, 113(1), 101-123. Retrieved from https://eric.ed.gov/?id=EJ1152556

Gabay, M. (2016). Time management of teachers and classroom engagement of pupils (Undergraduate thesis, Mindanao State University, General Santos City, Philippines).

Gomes, S., Jankowska, A., Polotskaia, A., \& Shaw, S. (2015). The relationship between health and academic performance: Implication for school psychologists. School Psychology International, 36(2), 115-134. https://doi.org/10.1177/0143034314565425

Hanks, A., Just, D., Smith, L., \& Wansink. B., (2012). Healthy Convenience: Nudging Students Toward Healthier Choices in the Lunchroom. Journal of Public Health, 34(3), 370-376. https://doi.org/10.1093/pubmed/fds003

Hubley, J., Copeman, J., \& Woodall, J. (2013). Practical health Promotion. Cambridge: Polity Press.

Huitt, W. (2007). Maslow's Hierarchy of Needs. Educational Psychology Interactive. Valdosta, GA: Valdosta State University. Retrieved from goo.gl/5ITr

Jensen, E. (2013). How poverty affects classroom engagement. Faces of Poverty, 70(8), 24-30.

Jiménez, A., Cortobius, M., \& Kjellén, M. (2014). Working with indigenous peoples in rural water and sanitation: Recommendations for an intercultural approach. Stockholm: SIWI.

Johnson, B. (2010). When rote learning makes sense. Retrieved from http://goo.gl/f3f1Vn

Kovess-Masfety, V., Ester, W. A., Wild, K., Bitfoi, A., Goelitz, D., Lesinskiene, S., ... Husky, M. M. (2020). Mental health problems, low birthweight and academic achievement in mathematics and reading. Current Psychology. https://doi.org/10.1007/s12144-020-00674-8

Kuh, G., Kinzie, J., Buckley, J., Bridges, B., \& Hayek, J. (2006). What matters to student success: A review of the literature. Retrieved from t.ly/js05

Kwan, S., Petersen, P., Pine, C., \& Borutta, A. (2005). Health-promoting schools: An opportunity for oral health promotion. Bulletin of the World Health Organization, 83, 
677-685. Retrieved from t.ly/Ifty

Leysa, S. (2011). Health practices and environmental awareness of education biology major students of Mindanao State University - General Santos City (Undergraduate thesis, Mindanao State University, General Santos City, Philippines).

Mara, D., Lane, J., Scott, B., \& Trouba, D. (2010). Sanitation and health. https://doi.org/10.1371/journal.pmed.1000363

Marques, A., Hillman, C., \& Sardinha, L. (2018). Physical activity, aerobic fitness and academic achievement. Health and Academic Achievement. https://doi.org/10.5772/intechopen.71284

Martin, J., \& Torres, A. (2016). User's guide and toolkit for the surveys of student engagement. Washington D.C.: National Association of Independent Schools

Matingwina, T. (2018). Health, Academic achievement and school-based interventions. Health and Academic Achievement. https://doi.org/10.5772/intechopen.76431

McCombes, S. (2019). Correlational research. Retrieved from t.ly/XSbk

Mcisaac, J., Kirk, S., \& Kuhle, S., (2015). The association between health behaviours and academic performance in Canadian elementary school students: A cross-sectional study. International Journal of Environment Research and Public Health, 12, 14857-14871. https://doi.org/10.3390/ijerph121114857

Michael, S. L., Merlo, C. L., Basch, C. E., Wentzel, K. R., \& Wechsler, H. (2015). Critical connections: Health and academics. Journal of School Health, 85(11), 740-758. https://doi.org/10.1111/josh.12309

O’Connor, M., Cloney, D., Kvalsvig, A., \& Goldfeld, S. (2019). Positive mental health and academic achievement in elementary school: New evidence from a matching analysis. Educational Researcher, 48(4), 205-216. https://doi.org/10.3102/0013189x19848724

Percalin, R. (2016). Healthy living programs and the health habits of grade 6 pupils (Undergraduate thesis, Mindanao State University, General Santos City, Philippines).

Richards, J. (2016). Here's why we can't stop sticking cotton buds in our ears. Retrieved from t.ly/HjwR

Sabia, J. J., \& Rees, D. I. (2015). Body weight, mental health capital, and academic achievement. Review of Economics of the Household, 13(3), 653-684. https://doi.org/10.1007/s11150-014-9272-7

Siona, N. (2016). Home-based involvement of parents and classroom engagement of the pupils (Undergraduate thesis, Mindanao State University, General Santos City, Philippines).

Suhrcke M., \& de Paz Nieves, C. (2011). The impact of health and health behaviours on educational outcomes in high income countries: A review of the evidence. Copenhagen: WHO Regional Office for Europe. 


\section{Macrothink}

Global Journal of Educational Studies

ISSN 2377-3936

2020, Vol. 6, No. 1

Taylor, L., \& Parsons, J. (2011). Improving student engagement. Current Issues in Education. 14(1), 1-34. Retrieved from http://goo.gl/S6ofeM

The Australian Parenting Website. (2015). Nutrition and healthy food for teenagers. Retrieved from t.ly/ci88

United Nations Department of Economic and Social Affairs. (2009). State of the World's Indigenous Peoples. Retrieved from http://t.ly/GjVf

Wenglinsky, H. (2001). Teacher classroom practices and student performance: How schools can make a difference. Statistics and Research Division. https://doi.org/10.1002/j.2333-8504.2001.tb01861.x

Williams, R. (2014). Inherited intelligence. The scientist. exploring life, inspiring innovation. Retrieved from http://goo.gl/NPE1Io

Willms, J. D. (2009). Student engagement at school: A sense of belonging and participation. Results from PISA 2000. Retrieved from t.ly/u Yaw

Woodhouse, A., \& Lamport, M. (2012). The relationship of food and academic performance: A preliminary examination of the factors of nutritional neuroscience, malnutrition, and diet adequacy. Christian Perspectives in Education, 5(1), 1-14. Retrieved from https://digitalcommons.liberty.edu/cpe/vol5/iss1/1/

Wurman, R. (2015). Why do kids ask so many questions? Retrieved from http://goo.gl/3jqqcw

Xiang, M., Gu, X., Jackson, A., Zhang, T., Wang, X., \& Guo, Q. (2017). Understanding adolescents' mental health and academic achievement: Does physical fitness matter? School Psychology International, 38(6), 647-663. https://doi.org/10.1177/0143034317717582

Yabut, I. (2014). Health-related practices and socio-emotional behavior of intermediate teachers (Undergraduate thesis, Mindanao State University, General Santos City, Philippines).

Yansaputri, I. S., \& Wijaya, H. E. (2017). The role of social emotional health on academic achievement of college students. GUIDENA: Jurnal Ilmu Pendidikan, Psikologi, Bimbingan Dan Konseling, 7(1), 23. https://doi.org/10.24127/gdn.v7i1.748

\section{Copyright Disclaimer}

Copyright for this article is retained by the author(s), with first publication rights granted to the journal.

This is an open-access article distributed under the terms and conditions of the Creative Commons Attribution license (http://creativecommons.org/licenses/by/3.0/). 